\title{
Do vermelho ao arco-íris: as representações sobre o movimento LGBT nas mídias do MST
}

\section{From red to rainbow: the representations on LGBT movement on MST media}

\section{Bruno Monteiro Duarte}

Brasil. Universidade Federal de Viçosa. Cientista Social e mestrando em Extensão Rural pela Universidade Federal de Viçosa. ID ORCID: https://orcid.org/0000-0002-6607-5318. E-mail: bruno.duarte@ufv.br. Colaboração: Pesquisa e redação.

\section{Sheila Maria Doula}

Brasil. Universidade Federal de Viçosa. Doutora em Antropologia Social pela Universidade de São Paulo com pós-doutorado no Programa Postdoctoral de Investigación en Ciencias Sociales, Niñez y Juventud do Conselho Latino-americano de Ciências Sociais. Atualmente é professora associada IV da Universidade Federal de Viçosa. ID ORCID: https://orcid.org/0000-0003-0310-9055. E-mail: sheiladoula@gmail.com. Colaboração: Redação e revisão.

\section{Douglas Mansur da Silva}

Brasil. Universidade Federal de Viçosa. Doutor em Antropologia Social pelo Museu Nacional-UFRJ com pós-doutorado no Instituto de Ciências Sociais da Universidade de Lisboa e no Programa de Pós-graduação em Antropologia Social do Museu Nacional. Atualmente é professor associado I da Universidade Federal de Viçosa. ID ORCID: https://orcid.org/0000-0003-3987-3004. E-mail:douglas.mansur@terra.com.br.Colaboração: Revisão.

\section{Resumo}

Este artigo analisa as representações sobre o movimento LGBT dentro das mídias do Movimento dos Trabalhadores Rurais Sem Terra (MST). Buscou-se investigar como as pautas da comunidade LGBTPQIA+ são incorporadas por um movimento social que representa uma população rural. A metodologia consiste em pesquisa documental, utilizando-se as mídias sociais do MST e o Jornal Sem Terra como fonte de dados. Para o desenvolvimento do trabalho, foram 
criados quatro eixos temáticos para classificar as publicações do MST sobre o movimento LGBT. Foi utilizada também a técnica de evocação de palavras para a análise das edições do Jornal Sem Terra. Toda a pesquisa foi guiada pela teoria das representações sociais, que possibilitou identificar as visões do MST sobre os LGBT e as transformações do Movimento ao longo dos anos.

Palavras-chave: Movimentos Sociais, Homossexualidade, Representações sociais.

\section{Abstract}

This article analyzes representations about the LGBT movement within the media of the Landless Workers Movement. We investigated how the LGBTPQIA+ community guidelines are incorporated by a social movement that represents a rural population. The methodology used was documentary research, having the social media on the MST and the Jornal Sem Terra as data sources. Four thematic axes were created to classify the publications of the MST on the LGBT movement. The word evocation technique was also used to analyze the editions of Jornal Sem Terra. The research was guided by the theory of social representations, which allowed to identify the MST's visions of LGBT people and to verify the transformations of the movement throughout the years.

Keywords: Social Movements, Homosexuality, Social Representations.

\section{INTRODUÇÃO}

Ao longo da segunda metade do século XX, começa a se mobilizar e organizar o movimento conhecido atualmente no Brasil como LGBT ${ }^{1}$ :movimento de Lésbicas, Gays, Bissexuais, Travestis e Transgêneros. No entanto, já na década de 1950, quando não existia um movimento social organizado no Brasil, apresentam-se iniciativas voltadas para a sociabilidade, como reuniões, assembleias e confraternizações. No livro Na trilha do arco-íris (SIMÕES; FACCHINI, 2009),

\footnotetext{
A denominação "LGBT" empregada neste artigo segue o modelo referendado pela I Conferência Nacional GLBT, superando a terminologia MHB: Movimento Homossexual Brasileiro. No entanto, a terminologia "LGBT" também está sujeita a contestações e disputas.
} 
os autores argumentam que nos anos seguintes (década de 1970) há a formação de jornais e grupos, como as publicações dos jornais Lampião da Esquina e ChanacomChana. Nesses espaços, as publicações serviram de referência para um movimento em fase inicial de formação, marcado por um cenário autoritário e repressivo da Ditadura Militar (1964-1985).

Simões e Facchini (2009) defendem que houve três momentos de organização e atuação. A primeira onda é datada pelo final da Ditadura Militar, em 1978, quando surge o então denominado "movimento homossexual" no Brasil. O segundo momento se deu durante o processo de democratização (década de 1980) e a mobilização em torno da Assembleia Nacional Constituinte (1987). Esse cenário coincidiu com a expansão do Vírus da imunodeficiência humana (HIV), demandando do movimento adequação aos novos contextos, com novas performances e estratégias de ação. Na terceira onda, a partir dos anos de 1990, o movimento encontra-se em parceria com o Estado e o mercado segmentado.

O movimento LGBT brasileiro se constrói com múltiplas fases, como um movimento heterogêneo, com disputas internas e demandas que se transformaram ao longo do tempo. Além disso, o movimento sofre a influência do movimento gay de luta por direitos dos Estados Unidos. Em 28 de junho de 1969, na cidade de Nova York, é datado por muitos como o marco zero do movimento $\mathrm{LGBT}^{2}$. Esse dia foi marcado pelo enfrentamento entre policiais e gays, lésbicas, travestis e drag queens. Tal episódio, conhecido como Rebelião de Stonewall, durou seis dias de repressões dos agentes do Estado, lançando as bases para o movimento pelos direitos LGBT no mundo.

Na década de 1980, a comunidade mundial LGBT enfrentou um grande golpe, que mudou significativamente todo o movimento, a epidemia do vírus HIV. A emergência de um pânico moral em torno dessa nova doença desencadeou novos estigmas sobre essa comunidade já marginalizada. De acordo com Cohen (1972), pânico moral é compreendido como um processo no qual um determinado grupo social, detentor de um status, começa a propagar a ideia

\footnotetext{
Consagrado posteriormente como o "Dia Internacional do Orgulho LGBT", torna-se uma data simbólica para celebrar vitórias históricas e os desafios na busca e consolidação do reconhecimento e dos direitos da comunidade de Lésbicas; Gays; Bissexuais; Travestis, Transexuais e transgêneros; Pansexuais; Queer; Intersexo; Assexuais; e, pessoas que não se sintam representadas por nenhuma das outras oito letras (LGBTQIA+).
} 
de que comportamentos ou atitudes de outro grupo, normalmente minoritário, e é capaz de configurar uma ameaça para a sociedade. Tal fenômeno gera uma aversão e repulsa ao grupo social em questão.

Para Sevalho, a epidemia da síndrome de imunodeficiência adquirida (Aids) trouxe uma série de preconceitos, atingindo inicial e principalmente os homossexuais masculinos. Nesse sentido, toda a comunidade LGBT passou a ser entendida como portadora e transmissora de uma doença incurável, denominada de "câncer gay" (SEVALHO, 1993, p. 352), criando, dessa forma, estigmas que até hoje se permanecem no imaginário social (BRASILEIRO; FREITAS, 2006, p. 5). Esse estigma social que recai sobre a comunidade LGBTPQIA+ coloca o grupo como inabilitado para uma aceitação social plena (GOFFMAN, 1988).

No âmbito das Ciências Sociais, o movimento LGBT tem obtido cada vez mais destaque em debates e estudos, pois tal movimento, e também o movimento feminista, são essenciais para a compreensão da sociedade contemporânea, principalmente no que se refere à temática da expansão do conceito de cidadania (NAZARÉ, 2011). Assim sendo, o movimento LGBT e feminista constroem um processo de politização da esfera pública, ao trazerem para o centro das discussões públicas questões como sexualidade, reprodução, trabalho doméstico, entre outras que vão para muito além da matéria sobre redistribuição econômica. Tal preocupação se torna essencial em uma sociedade na qual a sexualidade é perpassada por um intenso caráter heteronormativo (BUTLER, 2003).

A heteronormatividade expressa um conjunto de demandas, expectativas e deveres sociais que têm como fonte o modelo heterossexual, assumido como sendo natural e primordial para a vida social (CHAMBERS, 2003; COHEN, 2005). A heteronormatividade enquadra as práticas, os atos e desejos, com base no modelo do casal heterossexual, compreendendo que todas as relações, mesmo as relações entre indivíduos LGBTPQIA+, são estabelecidas a partir do binarismo de gênero (MISKOLCI, 2007, 2009).

O movimento LGBT no Brasil teve consistente organização e expansão após a criação da Associação Brasileira de Gays, Lésbicas e Transgêneros (ABGLT), 
em $1995^{3}$. Essa entidade começou a mobilizar e acionar diversos novos atores sociais e estatais, a exemplo de suas ações no âmbito do Executivo e Legislativo Federal, além da importante luta travada no interior do Judiciário, no qual conseguiu diversas ampliações dos direitos dos LGBT, como o reconhecimento da união homoafetiva (2011), a constitucionalidade da possibilidade de homens homossexuais doarem sangue (2017) e a alteração de gênero de pessoas trans no assento de registro civil (2017) (DUARTE, 2016).

Nessa perspectiva, o movimento LGBT tem conquistado direitos e suas pautas estão entrando na ordem do dia de forma cada vez mais eficaz do que em décadas passadas. No entanto, a população LGBTPQIA+ é ainda estigmatizada e vítima de diversos preconceitos, além de ter diversos direitos ainda cerceados no Brasil, colocando em dúvida a sua efetiva cidadania. Quando se aborda essa minoria localizada no meio rural brasileiro, surgem diversas particularidades.

Cada vez mais, a literatura vem abordando os preconceitos que a população LGBTPQIA+ sofre nas regiões rurais. Para alguns autores o rural tem como uma das características a maior "cristalização de valores e costumes", além da divisão sexual do trabalho ser um dos pilares da agricultura familiar. Nesse sentido, Eribon (2008) argumenta que as cidades sempre foram um "refúgio" para essa população de minorias, causando o que Martins, Rosa e Orlandi (2013) chamam de "diáspora gay", na qual esse grupo de pessoas busca nas cidades (no urbano) uma hipotética liberdade sexual e de ser. Assim sendo, a vivência da homossexualidade tem profunda relação com o metropolitano, pois o urbano é representado como "um mundo de estranhos", que "permite preservar o anonimato e, portanto, a liberdade, no lugar das pressões sufocantes das redes de entreconhecimento que caracterizam a vida nas cidades pequenas" (ERIBON, 2008, p. 34).

\footnotetext{
3 Este artigo aborda o termo "movimento LGBT" para designar um movimento social fragmentado, com diversas pautas e atores, que muitas das vezes estão em conflito. No entanto, eles possuem um objetivo em comum, que é a igualdade social para as pessoas LGBTPQIA+. Nesse sentido, tem-se a ABGLT, fundada em 1995, e posteriormente, a partir dos anos 2000, começam a surgir diversas redes nacionais de luta por direitos LGBT, como por exemplo: a Articulação de Travestis, Transexuais e Transgêneros (Antra), criada em 2000; a Liga Brasileira de Lésbicas (LBL), criada em 2003; a Articulação Brasileira de Lésbicas (ABL), criada em 2004; o Coletivo Nacional de Transexuais (CNT) e a Rede Afro-LGBT, criadas em 2005; o Coletivo Nacional de Lésbicas Negras Feministas Autônomas (Candace), criado em 2007; o E-Jovem, que tem se articulado desde 2001; e a Associação Brasileira de Gays (Abragay), fundada em 2005.
} 
Todavia, não se busca aqui uma compreensão desenvolvimentista e/ ou heteronormativa. Gontijo e Costa (2012, p. 183) alertam que não se deve "reproduzir a verdade não questionada de um 'urbano' civilizador que deve se sobrepor a um 'rural' a ser civilizado". Outro ponto relevante a ser pensado é que não são todos os membros da comunidade LGBTPQIA+ rurais que embarcam numa "diáspora" rumo ao mundo urbano; muitos vivem nas regiões rurais e, de forma diferente dos metropolitanos, articulam as suas próprias resistências frente à heteronormatividade.

Assim sendo, refletindo sobre como o movimento LGBT e suas pautas são interpretadas, recebidas e propagadas no universo rural brasileiro, buscou-se como foco de análise as representações do Movimento dos Trabalhadores Rurais Sem Terra (MST) sobre o movimento LGBT. Tal escolha parte da compreensão da importância que o MST assume para um expressivo grupo social de trabalhadores rurais, por sua significativa institucionalização, além de ter uma grande capilaridade nos universos rurais brasileiros, tornando-se nesse sentido um interessante movimento a ser pesquisado. O MST, criado no início da década de 1980, passou por um processo de nacionalização e atingiu o status de principal movimento social do campo no Brasil, tendo como objetivos principais: lutar pela terra, por Reforma Agrária e por uma sociedade mais justa e fraterna (MST, 2009).

Certamente, vale ressaltar o papel de movimento social do MST e do movimento LGBT, que como quaisquer outros movimentos sociais, surgem do que Melucci (2001) define como ausência de reconhecimento de uma identidade coletiva, gerada a partir de um campo de conflito no ambiente político, social e econômico. Assim sendo, o MST e o movimento LGBT carregam em si uma forte ação de construir a identificação coletiva, com afinidades de demandas por direitos. Essa capacidade de gerar demandas coletivas por certos benefícios exige uma sustentação de identidade que coloca os membros desses grupos conectados. Nesse sentido, na dinâmica social contemporânea as pautas de ambos os grupos tendem a se cruzar, como por exemplo na Resolução nº 35 do Ministério do Desenvolvimento 
Agrário de 2014, que dispõe sobre a oficialização do direito do casal homossexual de ser assentado junto, e não mais como solteiros.

Considerando-se que o movimento LGBT vem conquistando cada vez mais protagonismo nos debates públicos e na constante busca de proteção de direitos, e de reconhecimento social, este artigo, a partir da Teoria das Representações Sociais, tem como objetivo analisar e compreender as representações do MST sobre as pautas das diversidades sexuais trazidas pelo movimento LGBT. Para tanto, serão analisadas as mídias sociais do MST e o Jornal Sem Terra.

\section{METODOLOGIA}

A pesquisa utiliza uma metodologia de caráter qualitativo, tendo como base a Teoria das Representações Sociais. Assim sendo, a adoção de um estudo descritivo-exploratório aparenta ser a melhor forma para a compreensão do objeto aqui exposto. Por meio de uma revisão de bibliográfica - na qualidade de ferramenta teórica - e a análise documental - como pesquisa empírica - busca-se compreender como são construídas as representações sociais sobre o movimento LGBT e as suas pautas em alguns canais de comunicação utilizados pelo MST.

O universo empírico selecionado para a análise documental foi dividido em duas partes. Primeiramente, foram analisadas as mídias sociais do $\mathrm{MST}^{4}$, sendo elas as páginas oficiais do movimento no Facebook e Instagram ${ }^{5}$. A página do MST no Facebook foi criada em 2010 e conta atualmente com quase 350 mil seguidores. Já no Instagram, foi criada mais recentemente, no início de 2017 e possui pouco mais de 70 mil seguidores. Ambas têm uma grande

\footnotetext{
4 Este trabalho compreende as mídias sociais a partir de Kaplan e Haenlein (2010, p. 61, tradução nossa): "A mídia social é um grupo de aplicativos baseados na Internet que se apoiam nos fundamentos ideológicos e tecnológicos da Web 2.0 e permitem a criação e a troca de conteúdo gerado pelo usuário”. Assim sendo, as mídias sociais são sistemas projetados para viabilizar a interação social por diversos formatos e plataformas, com o intuito de compartilhar e criar informações a baixo custo e fácil engajamento. As mídias sociais podem ter diferentes formatos, como blogs, videologs, mensagens instantâneas, plataformas de compartilhamento de música, vídeos e mensagens, e-mail etc.

5 O Instagram e o Facebook são mídias sociais on-line de compartilhamento de fotos, vídeos e textos entre seus usuários.
} 
atividade, com média diária atual de 3 a 4 publicações $^{6}$. Nessa etapa da pesquisa, a análise se concentrou nas fotos, pequenos vídeos e legendas de fotos e vídeos compartilhados pelas páginas do Movimento.

Na segunda etapa da pesquisa foi analisado o Jornal Sem Terra (JST). Criado em 1980, o boletim buscou articular a formação política do MST, num momento de nacionalização do Movimento. O jornal configura-se, e é entendido pelo MST, como um importante veículo de publicação e comunicação (MST, 2018). Para a pesquisa, foi realizado um corte temporal de quatro anos de publicações do JST, de janeiro de 2011 até dezembro de 2014, somando dezoito boletins (da edição 309 até a 326).

Esse recorte temporal de análise foi selecionado devido à divulgação e disponibilidade dos boletins na íntegra, gratuito e de fácil acesso ao público no site oficial do MST. Além disso, o período de 2011 a 2014 se caracterizou por constates lutas, conquistas e perdas do movimento LGBT no Brasil, como a consolidação do Conselho Nacional de Combate à Discriminação e do Plano Nacional de Promoção da Cidadania e Direitos Humanos de LGBT, ao longo do governo Dilma Rousseff do Partido dos Trabalhadores (2011-2016). Foi também um período do reconhecimento e equiparação da união homoafetiva à união estável e à oficialização do direito do casal homossexual de ser assentado em conjunto. No entanto, houve também muito embate, como por exemplo o enfrentamento no Legislativo Federal sobre o programa "Escola sem Homofobia", em 2011, denominado pejorativamente de "kit gay", dentre outras lutas e retrocessos.

\section{MOVIMENTO LGBT E REPRESENTAÇÕES SOCIAIS}

A comunidade LGBTPQIA+ tem como configuração sujeitos de sexualidade estigmatizada que, há anos no Brasil e no mundo, enfrentam diversas lutas públicas em busca por reconhecimento nos múltiplos âmbitos sociais, políticos e jurídicos (HONNETH, 2003). Os indivíduos dessa comunidade, como em diversos outros grupos estigmatizados, tendem a se agrupar como

6 Média aritmética realizada entre os dias 20 de setembro até o dia 20 de outubro de 2018. 
forma de fortalecimento, onde os seus membros compartilham as mesmas particularidades e vivências. A aproximação desses indivíduos pode gerar um sentimento de pertencimento ao mesmo grupo, além disso o contato entre membros de uma determinada categoria pode modificar e ressignificar a compreensão mútua de ambos indivíduos, gerando mais vínculos de identidade social (GOFFMAN, 1988).

Tal relação se dá, pois, a sociedade cria meios para categorizar os indivíduos, a partir de atributos tidos como naturais. Goffman define a "identidade social" como conceito de distinção social, não utilizando o termo "status social", pois as categorias sociais criadas vão muito além das ocupações ou atributos estruturais econômicos. Valores como a "honestidade" ou "homens afeminados" se adequam melhor ao conceito de "identidade social”. "Quando um estranho nos é apresentado, os primeiros aspectos que nos permitem prever a sua categoria $\mathrm{e}$ os seus atributos, é a sua 'identidade social"' (GOFFMAN, 1988, p. 5).

Nesse sentido, o estigma se constitui quando um indivíduo estranho é apresentado e situado em uma determinada categoria que não é aceita, podendo ser interpretado de forma negativa ou diminuída. Goffman (1988, p. 7) argumenta que: "um indivíduo que poderia ter sido facilmente recebido na relação social quotidiana possui um traço que pode-se impor à atenção e afastar aqueles que ele encontra, destruindo a possibilidade de atenção para outros atributos seus".

$\mathrm{O}$ autor distingue três tipos de estigmas. Primeiramente, tem-se o estigma sobre a abominação do corpo e suas deformidades físicas. O segundo é o estigma tribal de raça, nação e religião. No entanto, este trabalho se interessa pelo último tipo, que é o estigma de culpas de caráter individual. Esse terceiro tipo é percebido pelo mundo social como "vontade fraca, paixões tirânicas ou não naturais, crenças falsas e rígidas, desonestidade" (GOFFMAN, 1988, p. 7). Exemplos de grupos que se encaixam nesse modelo de estigma são os prisioneiros, os doentes mentais e a comunidade LGBTPQIA+.

A comunidade LGBTPQIA+, como grupo estigmatizado, tem como característica central na sua situação de vida a "aceitação". Para Goffman, as pessoas estigmatizadas, como forma de responder aos estigmas, buscam corrigir diretamente o que pode ser considerado pelo meio social como 
"defeito". Nesse sentido, muitos homossexuais realizam tratamentos psicológicos e terapêuticos para se reajustar à sociedade, da mesma forma que um deficiente físico busca a cura para sua doença. Tais ações podem gerar o que Goffman (1988, p. 11) descreve: "Onde tal conserto é possível, o que frequentemente ocorre não é a aquisição de um status completamente normal, mas uma transformação do ego: alguém que tinha um defeito particular se transforma em alguém que tem provas de tê-lo corrigido".

Nessa perspectiva, os encontros dos "normais" com as pessoas estigmatizadas são momentos em que ambas as partes enfrentaram as causas e os efeitos do estigma. As pessoas estigmatizadas, nas interações sociais, tendem a sentir-se inseguras, tentando prever a forma como os "normais" o classificarão e o receberão. Os indivíduos estigmatizados receiam ter as suas ações interpretadas, como se fossem "uma expressão direta de seu atributo diferencial estigmatizado" (GOFFMAN, 1988, p. 16). Exemplo disso são os ex-pacientes mentais, que evitam debates acalorados com as pessoas, devido ao medo de uma interpretação equivocada sobre as suas emoções.

Dentro da sociedade, há um conjunto de indivíduos com os quais os estigmatizados podem receber um amparo. Primeiro, tem-se o apoio dos outros indivíduos que também sofrem do mesmo estigma, compreendendo-se dessa forma como iguais. O segundo grupo de apoio são dos que Goffman (1988, p. 27) chama de "informados", termo que os homossexuais definem os "normais", "cuja situação especial levou a privar intimamente da vida secreta do indivíduo estigmatizado e a simpatizar com ela, e que gozam, ao mesmo tempo, de uma certa aceitação, uma certa pertinência cortês ao clâ".

Os indivíduos "normais", para se transformarem em "informados", precisam viver uma experiência pessoal de arrependimento, para posteriormente serem aceitos pelos membros do grupo estigmatizado. Goffman (1988, p. 28) dá o exemplo dos garçons de bares frequentados pela comunidade gay, as empregadas das prostitutas de Mayfair e até os agentes policiais e os criminosos, pois se cria uma relação ao lidar constantemente com os criminosos.

Existe também um segundo tipo de indivíduo "informado", aquele que possui relações sociais com os estigmatizados através da estrutura social. Essa 
relação faz com que o "informado" passe a pertencer à mesma categoria na qual se encontram os estigmatizados. Nesse sentido, temos os filhos de presidiários, $\mathrm{O}$ cônjuge do paciente mental, ou ainda os simpatizantes e amigos dos LGBTPQIA+. Nessa relação, ambos indivíduos são forçados a compartilhar, mesmo que em menor grau, o descrédito do estigmatizado com o qual eles se relacionam, passando a viver dentro do mundo do estigmatizado (GOFFMAN, 1988, p. 28).

Diante disso, o estigma se constitui como mais uma das representações sociais geradas pela a sociedade. Um dos primeiros autores a teorizar sobre as representações sociais foi Moscovici (2001), que resgata na obra de Durkheim o conceito de representações coletivas, que pode ser entendido como "um conjunto de saberes que são produzidos por uma sociedade em sua globalidade" (DESCHAMPS; MOLINER, 2009, p. 101). No entanto, ao elaborar a sua teoria das representações sociais, Moscovici argumenta que "não só as nossas imagens do mundo social são um reflexo dos eventos do mundo social, mas os próprios eventos do mundo social podem ser reflexos e produtos de nossas imagens do mundo social" (SÊGA, 2000, p. 132).

Para Jodelet (2001, p. 17), as representações sociais não podem ser concebidas a partir de um isolamento social do indivíduo, mas sim num mundo de intercâmbio entre as pessoas, que buscam tanto apoio, quanto conflito, para ser capaz de "compreendê-lo, administrá-lo ou enfrentá-lo" . Nessa perspectiva, a autora defende que "as representações sociais são uma forma de conhecimento socialmente elaborado e compartilhado com um objetivo prático e que contribui para a construção de uma realidade comum a um conjunto social" (JODELET, 2001, p. 22).

Assim sendo, as representações sociais concebidas sobre a comunidade LGBTPQIA+ são tidas como se fossem "fruto de algo natural", da mesma forma como são aquelas construídas sobre a Mulher, como defende Pesavento (1998). Essas identificações sexuais, ou de gênero, são produzidas "a partir de papeis culturais e sociais historicamente construídos, e as representações induzem o olhar e o julgamento, pautam os comportamentos e normatizam as práticas" (PESAVENTO, 1998, p. 50).

Portanto, as representações sociais são produzidas com base nas diversas transformações que resultam em novos conteúdos. Sêga (2000) sustenta que 
no meio dessas transformações, o mundo que cerca os indivíduos é afetado tanto pelas representações, quanto fruto dessas representações. Nesse sentido, o autor argumenta que para Moscovici: "os preconceitos são dificilmente dissipados, os estereótipos não são enfraquecidos pois, para Moscovici, não existe nada na representação que não esteja na realidade, exceto a representação em si” (SÊGA, 2000, p. 132).

Nesse ínterim, Jodelet (2001) defende a importância da comunicação nos fenômenos representativos, pois ela é uma transmissora da linguagem, que é portadora por ela mesma da representação. Além disso, a comunicação media o processo de interação social, gerando consenso, disputa, conflito e influência. A autora considera que a comunicação também é capaz de construir representações, que quando são sustentadas por uma "energética social" se tornam relevantes para a vida dos grupos. Portanto, "energética e pertinências sociais que explicam, juntamente com o poder performático das palavras e dos discursos, a força com a qual as representações instauram versões da realidade, comuns e partilhadas" (JODELET, 2001, p. 32). Posto isso, pensar o Jornal Sem Terra e as mídias sociais do MST como lugares privilegiados de comunicação no seu nicho social, torna-se extremamente relevante na análise das representações sociais construídas e compartilhadas.

\section{ANÁLISE DOS DADOS}

A pesquisa documental constitui-se de duas etapas. Na primeira, foram analisados a página oficial do MST no Facebook (corte temporal se entende do ano de sua criação, 2010, até outubro de 2018) e o perfil oficial do MST no Instagram (corte temporal se entende do ano de sua criação, início de 2017, até outubro de 2018). Dessa forma, pretendeu-se constatar como as mídias sociais do MST representavam ou reagiam às pautas e valores do movimento LGBT. Após a leitura do material, foram criados quatro eixos temáticos, nos quais foram separadas todas as publicações. 
Os eixos são: "Espaço de visibilidade para as pautas LGBT", no qual o MST abria as suas mídias sociais para compartilhar determinadas pautas e lutas empreendidas pelo movimento LGBT. O segundo é "Convocação/divulgação de manifestação em conjunto ou em apoio" ao movimento LGBT. O terceiro eixo foi "Relatos/depoimento de LGBT Sem Terra", no qual era compartilhado ou noticiado depoimento por parte de um indivíduo LGBT que faz parte do MST. Por último, "Curso de formação política para LGBT Sem Terra", com o intuito de divulgar nas mídias sociais cursos de formação dentro da temática LGBT.

Com quase 350 mil seguidores, e uma atividade constante de compartilhamento e interação ${ }^{7}$, a página oficial do MST na rede social do Facebook divulgou 64 publicações sobre a comunidade LGBTPQIA+, entre o período de 2010 a outubro de 2018. O Gráfico 1 demonstra como as publicações se distribuíram ao longo dos nove anos da página.

\section{Gráfico 1: Publicações do MST no Facebook com a temática LGBTPQIA+.}

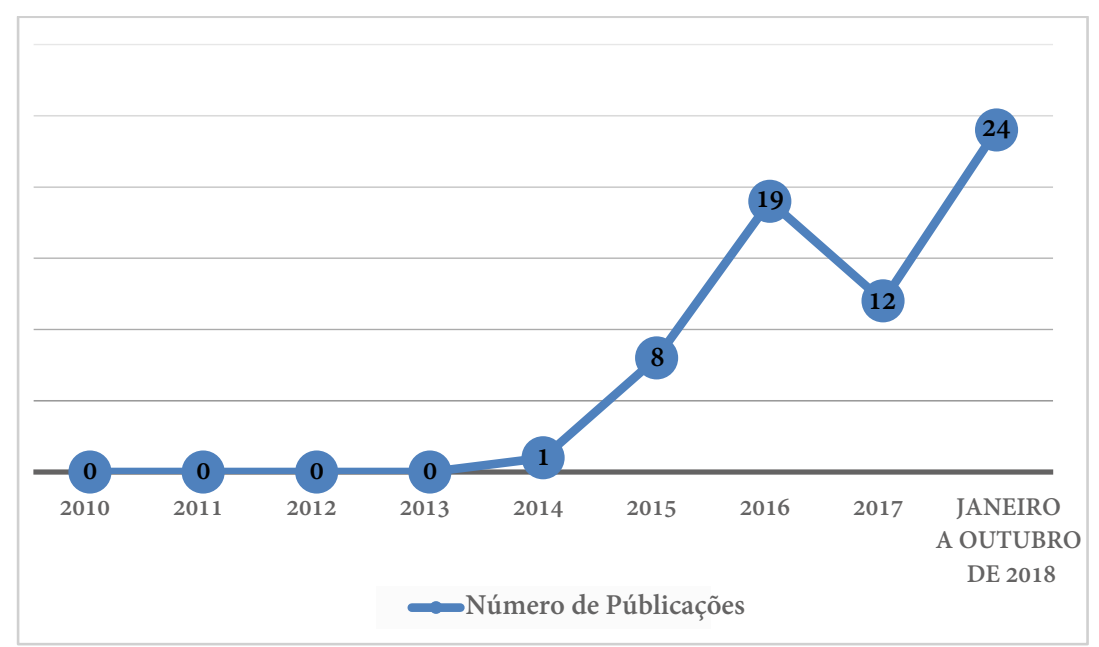

Fonte: Dados da pesquisa, 2018.

Pode-se perceber que as publicações com temáticas LGBTPQIA+ vêm aumentando ao longo dos últimos quatro anos, chegando ao número de 24 publicações em apenas dez meses de 2018. E como o MST só começa a dialogar

Ao longo desses nove anos, a página compartilhou pouco mais de 10 mil publicações. 
nas mídias sociais com as pautas do movimento LGBT a partir de 2014, antes havia um silêncio sobre os temas que, em 2018, se tornaram mais visíveis. Exemplo disso é o "Dia internacional contra a homofobia", comemorado no dia 17 de maio, que ao contrário do que normalmente acontece em datas de reivindicação internacional contra algum tipo de exclusão, o MST até o ano de 2014, não divulgou nenhuma publicação nas suas redes sociais.

Essa ausência das pautas do movimento LGBT é de difícil compreensão. Como colocado por Jodelet (2001), são necessários a interação social e o intercâmbio de comunicação para se construir as representações sociais. Nesse sentido, constitui uma missão incerta (para não se dizer inviável) concebê-las com base em um isolamento social ou em uma rede silenciosa. No entanto, pode-se levantar algumas hipóteses, retomando as contribuições de Goffman (1988), que a comunidade LGBTPQIA + se constitui como grupo estigmatizado frente a uma sociedade heteronormativa, tendo em suas pautas uma "natural" rejeição social, por ir de encontro com o status quo da família "tradicional", principalmente no meio rural com quem o MST quer se comunicar.

No entanto, com início em 2014, o MST começa a compartilhar na sua página do Facebook matérias que englobam a comunidade LGBTPQIA+. Uma hipótese para esse fenômeno seria a de que, como descreveu Goffman (1988), na sociedade os grupos estigmatizados podem receber amparo de outros indivíduos que também são vítimas de estigma, compreendendo-se dessa forma como iguais. Vale destacar que diversos estudos de classe, gênero, raça, sexualidade e suas interseccionalidades demonstram que relações de poder entre esses grupos podem ser dissimétricas (HIRATA, 2014), ou ainda haver relações de conflito, tensão e hierarquização entre grupos subalternizados. Porém, observa-se que em relação às publicações das mídias sociais do MST, com foco no grupo LGBTPQIA+, há uma possível convergência de interesses e identificação a partir de 2014.

Exemplo disso foi a criação de um coletivo denominado "LGBT Sem Terra" dentro do MST, no ano de 2014. O coletivo foi legitimado durante o Encontro da Coordenação Nacional do MST, na Escola Nacional Florestan Fernandes, em Guararema, no interior de São Paulo. Um grupo de lésbicas, gays, bissexuais, travestis e transexuais, pertencentes às bases do MST formou esse 
coletivo com o objetivo de criar uma unidade de luta contra a LGBTfobia nos assentamentos e acampamentos do MST, e também promover ações que extrapolam esses espaços, focalizando os desafios da conjuntura política nacional.

O coletivo LGBT Sem Terra começa a se afirmar como alvo de outro estigma, que ultrapassa o sofrido pelos trabalhadores rurais sem-terra, com o qual ele também se identifica, e que vai ao encontro do movimento LGBT. De acordo com um integrante do coletivo:

A construção de um projeto de Reforma Agrária Popular só é possível se compreendermos a sexualidade humana como parte fundamental da luta pela terra. A existência e resistência ativa desses sujeitos LGBT Sem Terra, que constroem o MST, é um alicerce importante no enfrentamento direto contra esse sistema patriarcal, racista e capitalista. Por isso, nós não voltaremos para o armário (LIMA, 2019).

Nesse sentido, o coletivo LGBT Sem Terra busca demonstrar que as pautas do MST são perpassadas por diversas outras, dentre elas a defesa da diversidade e dos sujeitos LGBTPQIA+. Nesse contexto específico, é valido pensar que grupos estigmatizados podem, em determinadas situações, ter maior facilidade de aceitação de outros grupos estigmatizados perante a sociedade (GOFFMAM, 1988). Isso é percebido também na fala de um integrante do LGBT Sem Terra, compartilhada na página do MST:

Só quem sofre discriminação sabe o quanto ela é dolorosa. E pelo fato de em algumas situações a gente ter sido discriminados por ser sem-terra, usar um boné vermelho, ser rotulado, isso fortalece a ideia de construir um novo homem e uma nova mulher. Não é um sujeito LGBT, como a gente brinca com os outros, mas um sujeito livre de qualquer mazela que possa reduzir nossa vida em rótulos (FREIRE, 2016).

O compartilhamento da dor do estigma social pode fazer com que grupos com pautas tão distintas unam-se em uma luta por reconhecimento. Esse cenário pode ser visto de forma mais ampla, como um movimento de diversos grupos sociais de esquerda, que passam a dialogar com pautas feministas, 
LGBT, raciais e outras que até pouco tempo atrás eram desvalorizadas ou deslegitimadas por uma esquerda ortodoxa, que tinha sua luta focada nas mazelas do capital e na opressão de classe. Essa virada das esquerdas, passando a incorporar novas pautas, não se limita a um movimento social específico, mas trata-se de um fenômeno muito mais amplo, como define Green (1994). Assim, se as temáticas do movimento LGBT estão aparecendo cada vez mais na rede social do MST, em quais categorias se encontram tais publicações? Como elas são absorvidas pelo MST? Essas questões merecem maior atenção.

Gráfico 2: Categorização dos conteúdos das publicações do MST no Facebook.

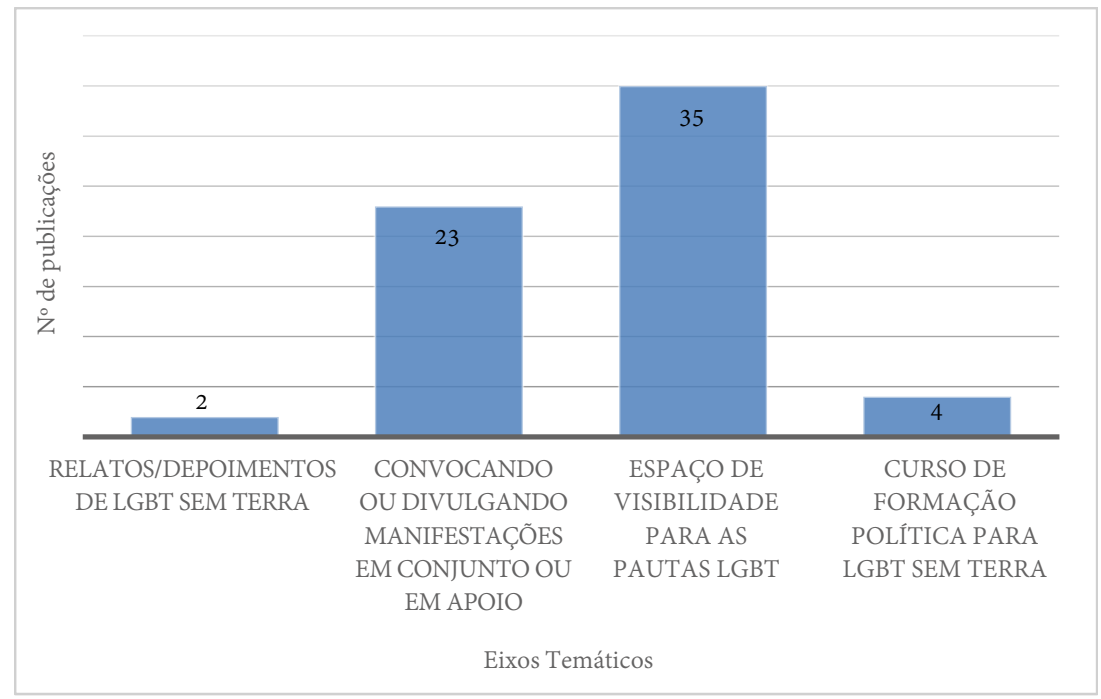

Fonte: Dados da pesquisa, 2018.

A maior parte das publicações se insere nos eixos "Espaço de visibilidade" e "Convocação/divulgação de manifestações". Mas se estratificar esse dado temporalmente, percebe-se que nos primeiros anos (2014, 2015 e 2016) há muito mais publicações do MST em apoio e visibilidade às pautas LGBTPQIA+. Já nos anos de 2017 e 2018 prevalecem as publicações que convocam ou divulgam manifestações em que o MST atua ao 
lado do movimento LGBT. Evidencia-se, dessa forma, três fases distintas de relação do MST com o movimento LGBT na sua página no Facebook: sai do silêncio sobre os LGBTPQIA+ (2010, 2011, 2012 e 2013), para uma postura de apoio e defesa das bandeiras dos LGBTPQIA+ (2014, 2015 e 2016) e, finalmente, percebe-se uma relação mais propositiva que se materializa na ação política nas manifestações em conjunto (2017 e 2018).

No Instagram, o perfil "MST Oficial” possui uma atividade diária de três a quatro publicações. Ela é mais recente do que a página do Facebook, pois foi criada no início de 2017 e alcançou um número de pouco mais de 70 mil seguidores. Ao longo desse período, foram compartilhadas quase 800 publicações, sendo que 23 publicações com referência ao movimento LGBT. A maioria das publicações se concentra nos 10 meses de 2018 (19 publicações).

A respeito do conteúdo das publicações do MST no Instagram (Gráfico 3), com base nos eixos citados anteriormente, a maior parte está centrada na abertura de "Espaço de visibilidade" para as pautas do movimento LGBT, diferentemente do constatado nos últimos anos no Facebook (Gráfico 2). Em relação ao número de publicação (entre 2017 e 2018), ambas as mídias sociais possuem um valor semelhante (algumas das vezes as publicações têm o mesmo conteúdo, sendo apenas replicadas). No entanto, vale ressaltar que nas publicações do Instagram constatou-se manifestações mais "progressistas", como, por exemplo, demonstração de carinho entre pessoas do mesmo sexo, que por terem suas sexualidades e identidades estigmatizadas, são de maior rejeição e repulsas pelos tidos "normais", como descreve Goffmam (1988). 
Gráfico 3: Categorização dos conteúdos das publicações do MST no Instagram.

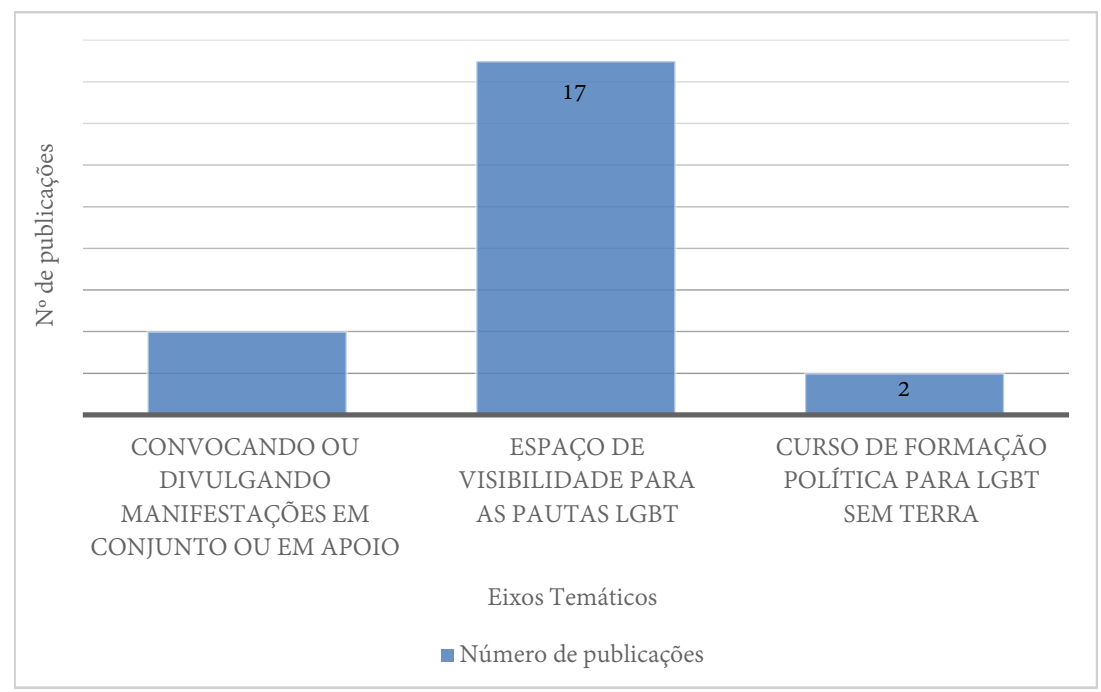

Fonte: Dados da pesquisa, 2018.

Com base nas análises das publicações, foi possível perceber que o MST se coloca nas mídias sociais de formas distintas ao longo dos anos. Além das temáticas que sempre permaneceram no percorrer do tempo (como: denúncias de violências contra o Movimento ou indivíduos do grupo, contra a grande mídia, agrotóxico, agronegócio e reforma agrária), o MST até o ano de 2015 possuía uma pauta específica e com apoio de grupos sociais bem distintos dos atuais (sindicatos de trabalhadores industriais, indígenas e uma pauta voltada para América Latina), e que a partir de 2015, principalmente, o MST começa a compartilhar cada vez mais publicações com um número maior de grupos sociais, como, por exemplo, pautas feministas, agroecológica, de juventude e sobre o movimento negro e o movimento LGBT.

Essa metamorfose pode ser vista nas fotos compartilhadas nas mídias sociais do MST (Figuras 1, 2 e 3), nas quais as manifestações inicialmente eram tomadas por bandeiras vermelhas do Movimento, e com o passar dos anos, as manifestações começam a ganhar novas colorações, cores de outros movimentos (movimento negro, feminista e LGBT principalmente). 
Figura 1: Duas manifestações do MST em 2014, em Brasília.

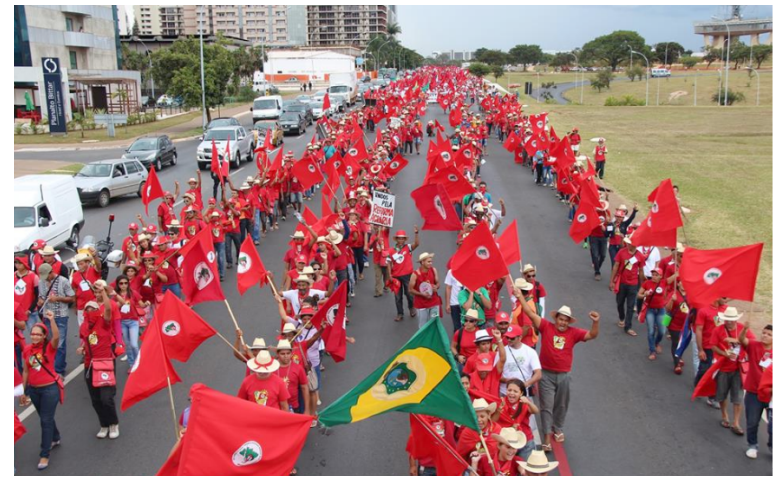

Fonte: Página oficial do MST no Facebook, 2014.

Figura 2: Coletivo do MST participando da Parada do Orgulho Gay 2016, em São Paulo.

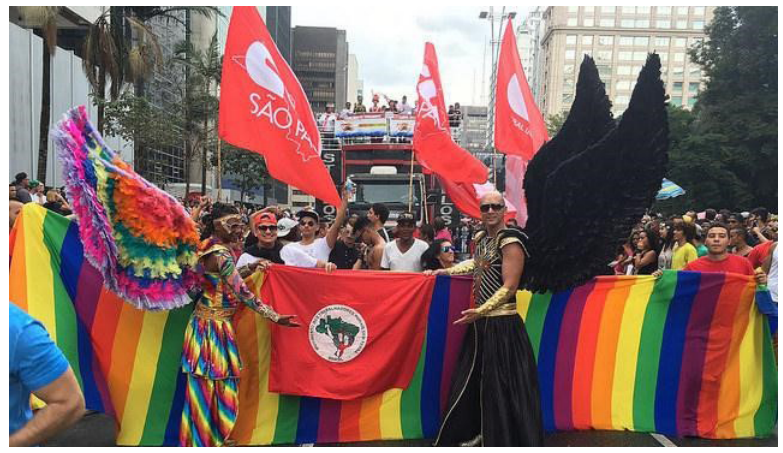

Fonte: Site oficial do MST, 2016.

Figura 3: Manifestação do MST em 2017, em Brasília.

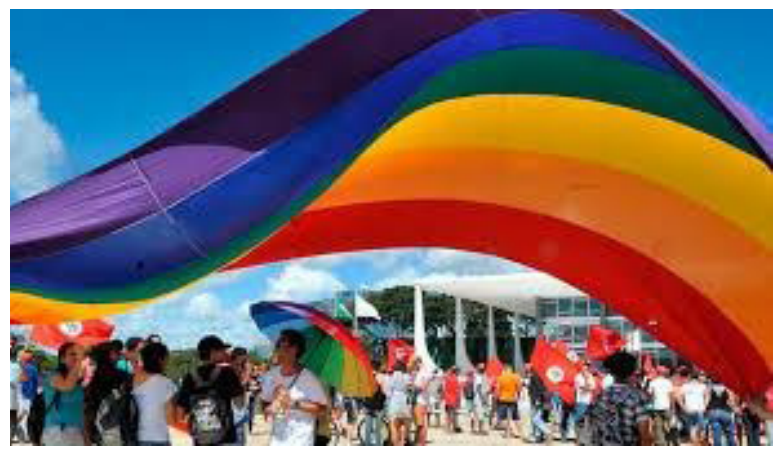

Fonte: Página oficial do MST no Facebook, 2017. 
Nesse sentido, o MST começa a legitimar e corroborar com o movimento LGBT; porém, mais do que representar as pautas LGBTPQIA+, o MST busca criar uma representação de si mesmo, por meio das suas mídias sociais, de que as pautas do movimento LGBT foram incorporadas e compartilhadas pelo Movimento, tendo em vista a forma crescente como o Movimento dos Trabalhadores Rurais Sem Terra vem expandindo sua cobertura sobre o movimento LGBT. Neste caso, inclui também o número crescente de cursos de formação política para agentes sem-terra LGBTPQIA+.

$\mathrm{Na}$ segunda etapa da pesquisa documental foram analisados os boletins do Jornal Sem Terra, um dos mais importantes veículos de comunicação do MST. Como dito, o corte temporal de estudo foi de quatro anos de publicações que se constituíram em dezoito edições do jornal (2011 até 2014). A análise se deu baseada metodologicamente na técnica de evocação de palavras, que como definem Brabo e Gomes (2013, p. 6), é uma técnica cujos resultados podem ajudar "a tornar explícitos o conteúdo e estrutura de possíveis representações sociais sobre determinados temas".

Para a análise do Jornal Sem Terra foi feita a contagem da evocação de onze palavras-chave que aparecem nos boletins (Gráfico 4), sendo elas: gênero; minoria; LGBT; homossexual; sexualidade; opção sexual; orientação sexual; gay; lésbica; transexual e travesti. Tais palavras foram selecionadas a partir da pertinência e constante abordagem delas nas publicações das mídias sociais do MST. Assim sendo, após a localização e a numeração dessas palavras-chave no jornal, foi possível classificá-las com base nos quatros eixos citados anteriormente para o estudo das mídias sociais do MST (Gráficos 2 e 3). 
Gráfico 4: Evocação de palavras-chave no Jornal Sem Terra.

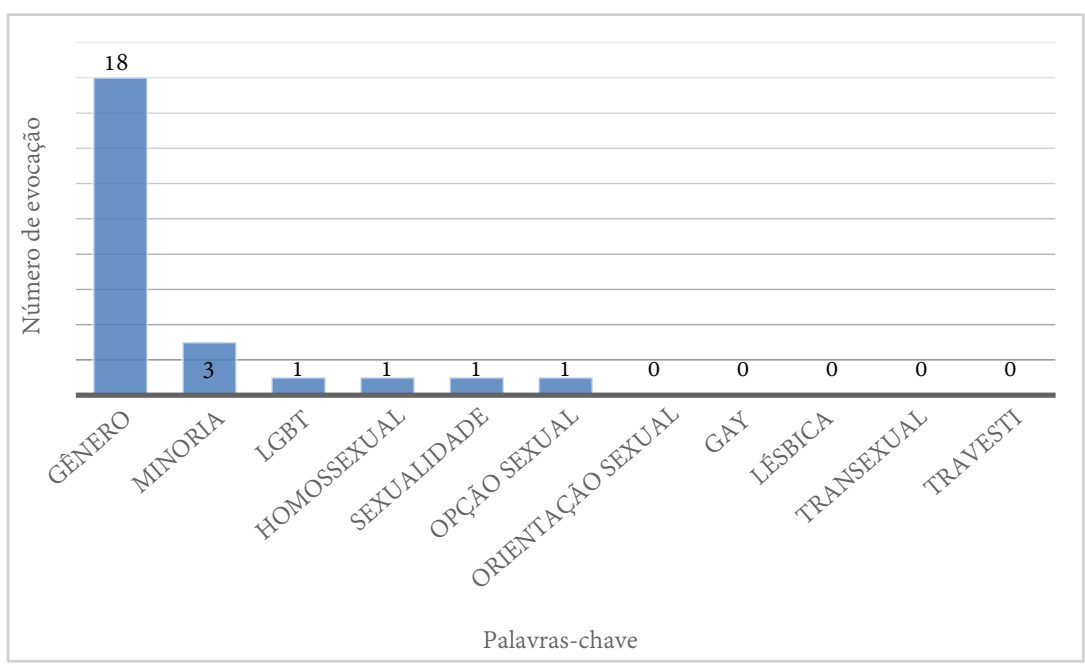

Fonte: Dados da pesquisa, 2018.

O termo mais citado nos dezoito jornais foi "gênero". No entanto, em todas as vezes que o termo aparecia, era em referência à "questão das mulheres" (mulheres heterossexuais e cisgêneros), abordando as desigualdades entre homens e mulheres, a violência contra a mulher no meio rural, ou no máximo de forma genérica e ampla do termo, sem abordagem transversal. Dentro dos eixos criados no texto, o termo "gênero" aparece como "Espaço de visibilidade" para as pautas das mulheres (8), "Relato/depoimento" de mulheres (5), "Convocação/divulgação" de manifestações referentes a questões feministas (3), ou ainda "Cursos de formação" política voltados para o público feminino (2).

A palavra-chave "minoria" é pautada três vezes, no entanto em nenhuma das vezes ela é voltada para o espectro LGBTPQIA+. Ela é utilizada apenas em referência ao próprio grupo do MST como uma minoria na arena política. Já o termo "LGBT" aparece apenas uma única vez, na edição número 326 de dezembro de 2014, dentro do eixo "Espaço de visibilidade", na qual se abordava a importância de uma Constituinte para o enfrentamento da sub-representatividade política de diversos grupos, dentre eles o LGBT.

Outro termo que tem apenas uma evocação é "homossexual", mas que não se encaixa em nenhum dos quatros eixos criados nesse trabalho, pois o termo 
surge de forma descritiva sobre um personagem em uma resenha literária, sem mais aprofundamento ou juízo de valor. As palavras-chave "sexualidade" e "opção sexual" possuem uma citação cada, ambas podendo ser classificadas dentro do eixo "Espaço de visibilidade".

Os termos "orientação sexual", "gay", "lésbica”, "transexual" e "travesti” não foram citados em nenhum momento ao longo dos quatro anos de edições do Jornal Sem Terra, distanciando-se, dessa forma, da característica crescente das mídias sociais do MST que assumiram uma postura de compartilhamento das pautas LGBTPQIA+ e adesão à parte do movimento LGBT. No entanto, vale a ressalva de que não se pode comparar as duas plataformas do MST (as mídias sociais e os jornais), tendo em vista que os cortes temporais das amostras são distintos.

Enquanto as mídias sociais (Facebook e Instagram) possuem cortes temporais que se estenderam desde a sua criação até os dias atuais, o Jornal Sem Terra foi analisado aqui com um corte temporal bem delimitado (2011-2014). Assim sendo, abre-se a possibilidade de pesquisas futuras focalizando o jornal com um corte temporal mais amplo e até os dias atuais, como foi feito aqui com as mídias sociais do MST, onde se constatou que as pautas e o movimento LGBT começaram a ganhar força a partir de 2014. Vale destacar que a primeira vez que o termo "LGBT" surge no Jornal Sem Terra foi na edição de dezembro de 2014, a última a ser analisada.

\section{CONSIDERAÇÕES FINAIS}

As representações sociais mudam constantemente e possuem uma dinamicidade. Dessa forma, as ações dos movimentos sociais estão em constate transformação, devido às suas relações com diversos processos sociais que influenciam estas mudanças. As redes de comunicação permitem a transferência e interposição não só de opinião e mitos, mas também de conhecimentos

\footnotetext{
Vale ressaltar que o termo "opção sexual" encontra-se em desuso. De acordo com o Manual de Comunicação da ABGLT (MARTINS et al., 2015, p. 15): "Essa expressão é incorreta. O termo aceito é 'orientação sexual'. A explicação provém do fato de que ninguém 'opta', conscientemente, por sua orientação sexual”.
} 
cristalizados, que foram produzidos ao longo do tempo pelo grupo. Nesse sentido, vê-se a importância da comunicação nos fenômenos representativos mediando todo o processo de interação social. Analisar as mídias do MST como ambiente de comunicação com seus membros é fundamental para a compreensão das representações sociais compartilhadas pelo grupo.

Como visto em todas as edições analisadas do Jornal Sem Terra e nos primeiros anos das mídias sociais, as pautas do movimento LGBT não tiveram espaço, havia um silêncio sobre o tema. No entanto, a partir de 2015, começam a surgir novas temáticas no interior da página do MST, dentre elas a do movimento LGBT. Inicialmente observa-se a abertura de espaço de visibilidade para as pautas desse grupo estigmatizado, mas com o tempo (principalmente após 2017) pode-se perceber que nas publicações do MST passaram a prevalecer as divulgações de manifestações em que os dois movimentos estariam juntos, ou ainda que o MST apoiaria a manifestação do movimento LGBT.

Ressalta-se que as publicações, assim como as representações sociais, estão inseridas em uma arena de disputa e conflito. A correlação do surgimento do coletivo "LGBT Sem Terra" (em 2014) e o aumento das publicações que abordam a comunidade LGBTPQIA+ está inserida em um contexto muito mais amplo, no qual os movimentos sociais de esquerda começaram a convergir nas suas pautas. Grande parte disso é devido aos processos de politização dos movimentos feministas e LGBT, que demandaram da esquerda a repensar assuntos como gênero, identidade e sexualidade, reformulando toda noção do marxismo ortodoxo, que concebia a ideia de que a diversidade sexual era a expressão de um “desvio burguês”, ou ainda que as pautas LGBT fossem subvalorizadas frente às pautas tidas como verdadeiramente importantes que eram a anticapitalista e opressão de classe.

Essas três fases, nas quais o MST representa o movimento LGBT nas suas mídias sociais, permite ver como o contato e a luta política podem modificar e ressignificar a compreensão mútua de ambos os coletivos, onde tanto os MST passa a ter manifestações mais "coloridas" (com um número muito maior de bandeiras diversificadas sendo levantadas em suas manifestações), ao mesmo tempo em que o movimento LGBT tem uma relativa receptividade com a 
causa do MST (como a presença da bandeira do MST nas Paradas Gay). Essa mudança demonstra que há uma construção de sentimentos de pertencimento ao mesmo status de estigmatizados.

As representações criadas no interior das mídias do MST não são idênticas às representações compartilhadas nos assentamentos ou nas comunidades rurais tradicionais, no entanto mostram como o MST se coloca em colisão com as representações sociais construídas ao longo da história sobre a comunidade LGBTPQIA+, grupo fortemente estigmatizado em sociedades heteronormativas. Assim sendo, torna-se de fundamental importância para o movimento LGBT essa mudança de posição que o MST assume nos anos recentes, pois possibilita a construção de uma transformação social, tendo em vista que as representações não são estáticas, e que ao entrarem em circulação pelos processos comunicativos, elas afetem a própria realidade na qual foram construídas.

\section{REFERÊNCIAS BIBLIOGRÁFICAS}

1. BRABO, Jesus C.; GOMES, Ana S. A. Teste de evocações semiestruturado como ferramenta para o estudo de representações sociais: possibilidades de aplicação na pesquisa em ensino de ciências. ENCONTRO NACIONAL DE PESQUISA EM EDUCAÇÃO EM CIÊNCIAS, 9., 2013, Águas de Lindóia. Anais [...]. Águas de Lindóia: Abrapec, 2013. p. 1-7.

2. BRASILEIRO, Marislei; FREITAS, Maria I. F. Representações sociais sobre aids de pessoas acima de 50 anos de idade, infectadas pelo HIV. Revista Latino-Americana de Enfermagem, Ribeirão Preto, v. 14, n. 5, p. 1-8, 2006.

3. BUTLER, Judith. Problemas de gênero: feminismo e subversão da identidade. Rio de Janeiro: Civilização Brasileira, 2003.

4. CHAMBERS, Samuel J. Telepistemology of the closet; or, the queer politics of six feet under. Journal of American Culture, Bowling Green, v. 26, n. 1, p. 24-41, 2003.

5. COHEN, Cathy J. Punks, bulldaggers, and welfare queen: the radical potential of queer politics? In: JOHNSON, Elondust P.; HENDERSON, Mae G. Black Queer Studies. Duke: Duke University Press, 2005. p. 188-193.

6. COHEN, Stanley. Folk Devils and Moral Panics: The Creation of the Mods and Rockers. London: MacGibbon and Kee, 1972. 
7. DESCHAMPS, Jean C.; MOLINER, Pascal. A identidade em psicologia social: dos processos identitários às representações sociais. Petrópolis: Vozes, 2009.

8. DUARTE, Bruno M. Os grupos sociais dentro de uma política judicializada. Revista Todavia, Porto Alegre, Série 2, v. 1, n. 1, p. 100-115, 2016.

9. ERIBON, Didier. Reflexões sobre a questão gay. Rio de Janeiro: Companhia de Freud, 2008.

10. GOFFMAN, Erving. Estigma: notas sobre a manipulação da identidade deteriorada. 4. ed. Rio de Janeiro: LTC, 1998.

11. GONTIJO, Fabiano S.; COSTA, Francisca C. S. "Ser Traveco é Melhor que Mulher": considerações preliminares acerca das discursividades do desenvolvimentismo e da heteronormatividade no mundo rural piauiense. Bagoas, Natal, n. 8, p. 171-186, 2012.

12. GREEN, James. A luta pela igualdade: desejos, homossexualidade e a esquerda na América Latina. Cadernos AEL, Campinas, v. 10, n. 18-19, p. 15-41, 2003.

13. HIRATA, Helena. Gênero, classe e raça: Interseccionalidade e consubstancialidade das relações sociais. Tempo Social, São Paulo, v. 26, n. 1, p. 61-73, 2014.

14. HONNETH, Axel. Luta por reconhecimento. São Paulo: Editora 34, 2003.

15. JODELET, Denise. As representações sociais. Rio de Janeiro: Eduerj, 2001.

16. KAPLAN, Andreas M.; HAENLEIN, Michael. Users of the world, unite! The challenges and opportunities of social media. Business Horizons, Bloomington, v. 53, n. 1, p. 59-68, 2010.

17. LIMA, Wesley. Nós não voltaremos para o armário. MST, [S. l.], 27 mar. 2019. Disponível em: https://bit.ly/35Rg5j8. Acesso em: 11 maio 2020.18. MARTINS, Emerson; ROSA, Rogério M.; ORLANDI, Renata. Jovens homens homossexuais na zona rural e heteronormatividade: resistências e processos de subjetivação. SEMINÁRIO INTERNACIONAL FAZENDO GÊNERO, 10., 2013, Florianópolis. Anais [...]. Florianópolis: Instituto de Estudos de Gênero, 2013. p. 1-12.

18. MARTINS, Ferdinando; ROMÃO, Lilian; LINDNER, Liandro; HARRAD, David; UNAIDS BRASIL (org.). Manual de comunicação LGBT: lésbicas, gays, bissexuais, travestis e transexuais. Niterói: ABGLT, 2015. Disponível em: https://bit.ly/2zszU4g. Acesso em: 11 maio 2020.

19. MELUCCI, Alberto. Invenção do presente: movimentos sociais nas sociedades complexas. Petrópolis: Vozes, 2001.

20. MISKOLCI, Richard. A teoria queer e a questão das diferenças: por uma analítica da normalização. CONGRESSO DE LEITURA DO BRASIL, 16., 2007, Campinas. Anais [...]. Campinas: Unicamp, 2007. p. 1-19. 
21. MISKOLCI, Richard. A teoria queer e a sociologia: o desafio de uma analítica da normalização. Sociologias, Porto Alegre, ano 11, n. 21, p. 150-182, 2009.

22. MOSCOVICI, Serge. Das representações coletivas às representações sociais: elementos para uma história. In: JODELET, Denise (org.). As representações sociais. Rio de Janeiro: Eduerj, 2001. p. 45-65

23. MST. Há 38 anos nascia o Jornal Sem Terra. MST, [S. l.], 15 maio 2018. Disponível em: https://bit.ly/3bjQr7T. Acesso em: 11 maio 2020.

24. MST. Objetivos. [S. l.: s. n.], 11 ago. 2009. Disponível em: https://bit.ly/2zt7p6m. Acesso em: 11 maio 2020.

25. NAZARÉ, Marcela P. B. O Movimento Homossexual Brasileiro: da clandestinidade à esfera pública. Revista Urutágua, Maringá, v. 24, p. 40-49, 2011.

26. PINA, Rute. LGBT: do campo à cidade, movimentos criam estratégias de combate à discriminação. Brasil de Fato, [São Paulo], 20 jul. 2016, 10:14. Disponível em: https://bit.ly/2zlzPQ5. Acesso em: 20 maio 2020.

27. PESAVENTO, Sandra. Catarina come gente. Imaginário, São Paulo, n. 4, p. 48-58, 1998.

28. SÊGA, Rafael A. O conceito de representação social nas obras de Denise Jodelet e Serge Moscovici. Anos 90, Porto Alegre, v. 8, n. 13, p. 128-133, 2000.

29. SEVALHO, Gil. Uma abordagem histórica das representações sociais de saúde e doença. Cadernos de Saúde Pública, Rio de Janeiro, v. 9, n. 3, p. 349-363, 1993.

30. SIMÕES, Júlio A.; FACCHINI, Regina. Na trilha do arco-íris: do movimento homossexual ao LGBT. São Paulo: Fundação Perseu Abramo, 2009. 